\title{
Johannes Vermeer's Mistress and Maid: new discoveries cast light on changes to the composition and the discoloration of some paint passages
}

\author{
Dorothy Mahon ${ }^{1}$, Silvia A. Centeno ${ }^{2 *}$, Margaret lacono ${ }^{3}$, Federico Caró ${ }^{2}$, Heike Stege $^{4}$ and Andrea Obermeier ${ }^{4}$
}

\begin{abstract}
Among the thirty-six paintings ascribed to the Dutch seventeenth century artist Johannes Vermeer (1632-1675), Mistress and Maid, in The Frick Collection, stands out for the large-scale figures set against a rather plain background depicting a barely discernible curtain. Although generally accepted as among the late works of the artist and dated to 1667-1668, for decades scholars have continued to puzzle over aspects of this portrayal. When the painting was cleaned and restored in 1952, attempts to understand the seeming lack of finish and simplified composition were hampered by the limited technical means available at that time. In 1968, Hermann Kühn included Mistress and Maid in his groundbreaking technical investigation 'A Study of the Pigments and the Grounds Used by Jan Vermeer.' In the present study, imaging by infrared reflectography and macro-X-ray fluorescence (MA-XRF) revealed significant compositional changes and drew focus to areas of suspected color change. Three of the samples taken by Hermann Kühn, and now in the archive of the Doerner Institut in Munich, were re-analyzed, along with a few paint samples taken from areas not examined in the 1968 study, using scanning electron microscopy-energy dispersive X-ray spectroscopy (SEM-EDS) and Raman spectroscopy. These analyses made it possible to further visualize detailed compositional elements in the background of the painting that were later painted out, and to characterize darkening and color changes in different paint passages.
\end{abstract}

Keywords: Johannes Vermeer, Mistress and Maid, Darkening, Color change, Underlying composition, MA-XRF, Raman spectroscopy, SEM-EDS

\section{Introduction}

When Henry Clay Frick purchased Vermeer's Mistress and Maid (Fig. 1a) in 1919, it joined two other paintings in his collection by this esteemed artist. By this time, the tacking margins had been removed and the original canvas support had been lined to a linen fabric with an aqueous glue/paste adhesive and stretched onto a keyable stretcher [1]. Despite its prominent placement today as the sole Vermeer in the West Gallery of Frick's

\footnotetext{
*Correspondence: silvia.centeno@metmuseum.org

${ }^{2}$ Department of Scientific Research, The Metropolitan Museum of Art, 1000 Fifth Avenue, New York, NY 10028, USA

Full list of author information is available at the end of the article
}

New York mansion, where it has remained on view for the most part since the collection opened to the public in 1935, there have been perennial questions about aspects of this painting. In 2017 Mistress and Maid was sent to The Metropolitan Museum of Art (The Met) for technical examination to clarify long standing issues in preparation for an in-focus publication [2].

Vermeer chose a large canvas for his composition, which presents two women pondering a newly arrived letter. The seated woman, dressed in elegant attire, is dramatically lit by an unseen light source that illuminates her marble-like skin and yellow mantle. Set before her is a table spread with a cloth on which lie a sheet of paper,
Springer Open

(c) The Author(s) 2020. This article is licensed under a Creative Commons Attribution 4.0 International License, which permits use, sharing, adaptation, distribution and reproduction in any medium or format, as long as you give appropriate credit to the original author(s) and the source, provide a link to the Creative Commons licence, and indicate if changes were made. The images or other third party material in this article are included in the article's Creative Commons licence, unless indicated otherwise in a credit line to the material. If material is not included in the article's Creative Commons licence and your intended use is not permitted by statutory regulation or exceeds the permitted use, you will need to obtain permission directly from the copyright holder. To view a copy of this licence, visit http://creativeco mmons.org/licenses/by/4.0/. The Creative Commons Public Domain Dedication waiver (http://creativecommons.org/publicdomain/ zero/1.0/) applies to the data made available in this article, unless otherwise stated in a credit line to the data. 


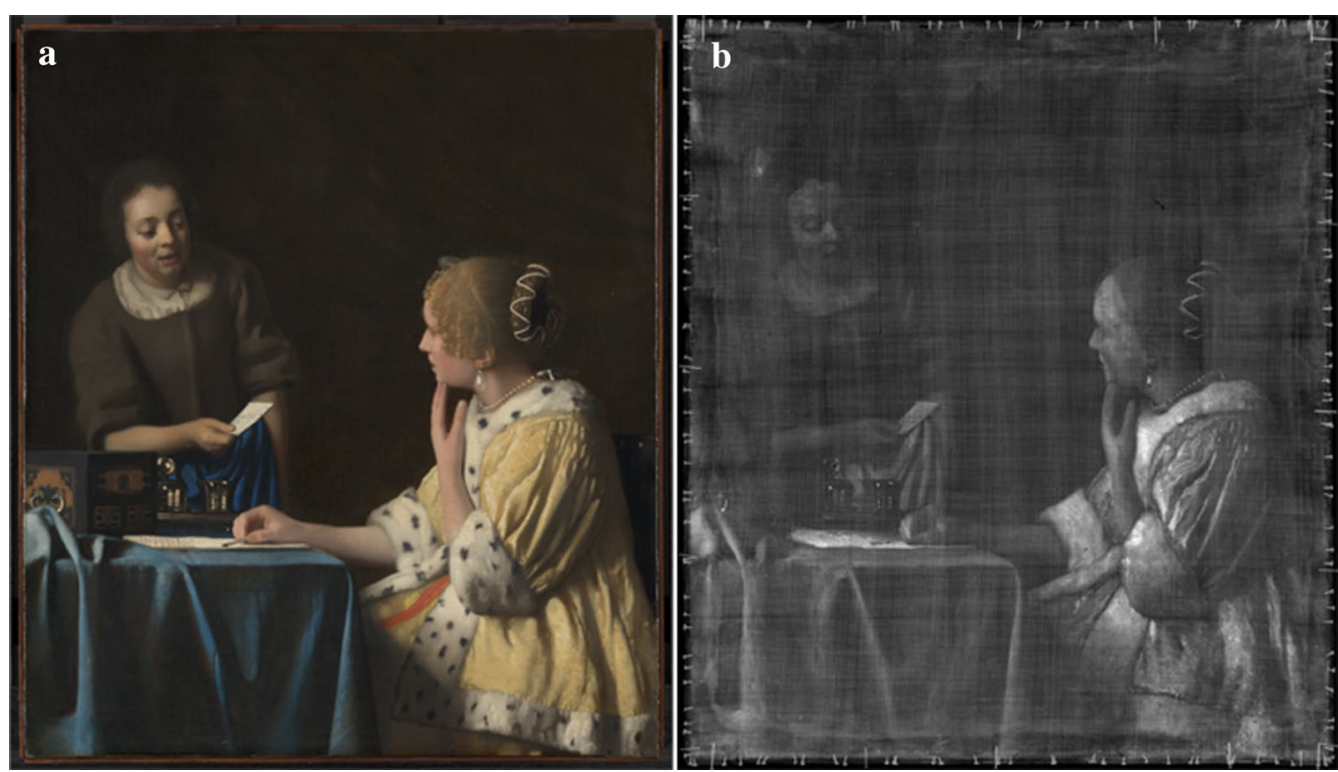

Fig. 1 Johannes Vermeer (1632-1675), Mistress and Maid, 1666-1667. Oil on canvas, 35 1/2 × 31 in. (90.2 × 78.7 cm). The Frick Collection, New York; Henry Clay Frick Bequest (a). X-radiograph (b)

a veneered box, and a collection of glass writing accessories places atop a silver tray. A modestly costumed maid emerges from the dark background to deliver a written message. The mistress's reaction, expressed by her hand stroking her chin, suggests her intense interest in the missive's arrival. The letter's inscrutable contents and the mistress's ambiguous response evoke a sense of mystery and uncertainty.

Depicting an interior domestic scene like so many of Vermeer's images, the painting explores the relationship between mistresses and maids and the writing and receiving of letters, two popular themes in the art and literature of the period. It also demonstrates Vermeer's technical virtuosity: bravura strokes suggest the pleating of the yellow mantle and the tablecloth's folds; shorter, bold strokes signify the flickering light reflected on the glassware; and dots of impasto convey the shimmer of the pearls.

There has been much debate among art historians as to whether or not the painting is finished [2-4]. Commentary includes suggestions that the appearance of the background, dark and empty except for a hint of a curtain, indicate that it was left unfinished in Vermeer's studio at this death and quickly finished up by another hand to make it saleable. This notion is reinforced by a 1809 line engraving by Jean-Baptiste-Pierre Lebrun published by Didot-Jeune, Paris, that records the composition in reverse, in which no curtain appears [5]. While a nearly featureless background is unusual for a genre scene by Vermeer, similar backgrounds are found in his tronies, for example, Girl with a Pearl Earring, 1665-1667 [6], in the collection of the Maurithuis, The Hague, and Study of a Young Woman, 1665-1667 [6], in The Met. When the painting was cleaned and restored in 1952, the conservator William Suhr added his opinion to the debate as to whether the painting was finished by asserting that the mistress's "face and neck, the left arm and hand [were] just underpainted, and the eye merely blocked in [1]". Using his skills as a connoisseur, Suhr goes on to assert that "the background is original and is a curtain" although he considers that it was never finished and that it consists of a glaze, dark brown in color [1]. He observes that "some of the mistress' curls and the ribbon of the pearl necklace....are painted over this brown."

Hermann Kühn was commissioned by the National Gallery of Art, Washington, to carry out a technical study of Vermeer that was published in 1968 [7]. This groundbreaking investigation included thirty of the thirty-five paintings considered at that time to be by Vermeer, and was limited to samples taken from the edges of the paintings studied. In 1965, Kühn took samples from Mistress and Maid from four locations: the ebony veneered box, the tablecloth, the mistress' yellow robe, and the fur trim. Samples taken from the first three locations listed were mounted in cross-section. The sample taken from the fur trim was a scraping. In addition to his assessment of the layer structure of the cross-sections, the pigment scraping from the fur trim and the unmounted material from the other three locations were analyzed. Kühn's analytical methods included light microscopy, microchemical tests, 
powder X-ray diffraction and emission spectrographic analysis (ESA). In Mistress and Maid, Kühn identified chalk, lead white, charcoal black, $\mathrm{Cu}$ resinate, natural ultramarine, and lead-tin yellow. Kühn also reported for all samples a thin brown-black layer applied over the ground layer, containing charcoal black.

Mistress and Maid has also been included in "Counting Vermeer: Using Weave Maps to Study Vermeer's Canvases," a the comprehensive multidisciplinary study of Vermeer's canvases [8].

In our study, with the aim to investigate the changes to the composition and the discoloration of some paint passages mentioned above, the cross sections taken by Hermann Kühn in 1965 were re-examined. X-radiography, infrared reflectography, and macro-XRF were used to image the entire painting, and three new samples from the background, an area not included in the Kühn's study, were analyzed.

\section{Experimental}

\section{X-radiography}

A TFI "Hotshot" portable industrial X-ray unit, consisting of a 603 head and 805D control, was used. The system has a $0.5 \mathrm{~mm}$ focal spot and $96.5 \mathrm{~cm}$ radiation beam. Images were recorded onto Industrex Flex XL Blue 5537 plates, and digitized with a Carestream HPX-1 scanner. Nine $14 \times 147$ inch captures were scanned at 508 ppi and digitized using nip.

\section{Infrared reflectography}

Infrared reflectography was done using an OSIRIS InGaAs near-infrared camera with a 6-element, $150 \mathrm{~mm}$ focal length, f/5.6-f/45 lens; and $900-1700 \mathrm{~nm}$ spectral response. A total of nine captures were made, each $11 \times 11$ inches and $4096 \times 4096$ pixels. The captures overlapped 25\% and were stitched using Photoshop.

\section{Macro-X-ray fluorescence (MA-XRF)}

Macro-X-ray fluorescence (MA-XRF) of Mistress and Maid was carried out using a Bruker M6 Jetstream instrument with the X-ray source operated at $50 \mathrm{kV}$ and $0.5 \mathrm{~mA}$. The full painting was mapped in four sections with a $700 \mu \mathrm{m}$ spot size and a $700 \mu \mathrm{m}$ step size, with a dwell time of $90 \mathrm{~ms} /$ pixel. The spectra were processed using the Bruker M6 Jetstream software.

\section{Samples}

Three samples were taken using a scalpel under high magnification, and were mounted as cross-sections in Technovit ${ }^{\circledR}$ resin and polished using Micromesh ${ }^{\circledR}$ cloth.

A set of three cross-section samples that had been taken by Hermann Kühn in 1965, and now in the archive of the Doerner Institut, were also analyzed. These samples were lightly repolished using Micromesh ${ }^{\circledR}$ cloth 8000 or 12,000 , depending on the condition and size of the sample.

\section{Optical microscopy}

At the Doerner Institut, an Axioskop 20 (Zeiss) microscope was used, with $50 \times, 100 \times, 200 \times, 500 \times$ and $1000 \times$ magnifications, a DIC incident light filter, 02 and 18 UV filter sets, a $12 \mathrm{~V}-100 \mathrm{~W}$ halogen lamp as VIS light source, a LQ-HXP 120 (Leistungselektronik Jena) with a HXP-R120W/45C VIS lamp (Osram) as UV light source, a $0.63 \times$ converter, a digital AxioCAM MRc (Zeiss) microscope camera with an AxioVision 4.9 software. For the examination of samples cross-sections at The Met, a Zeiss Axio Imager M2m microscope was used, with $50 \times$, $100 \times, 200 \times$ and $500 \times$ magnifications, an Axiocam HRc digital camera and AxioVision 4.X.X software.

\section{Raman spectroscopy}

Raman spectroscopy measurements were done on the three sample cross-sections taken at The Met for the present study using a Renishaw System 1000 coupled to a Leica DM LM microscope. All the spectra were acquired using a $785 \mathrm{~nm}$ laser excitation focused on the samples using a $50 \times$ objective lens, with integration times between 10 and $120 \mathrm{~s}$. A 1200 lines/mm grating and a thermoelectrically cooled CCD detector were used. Powers at the sample were set between 0.5 and $5 \mathrm{~mW}$ using neutral density filters.

The cross-sections housed at the Doerner Institut in Munich were analyzed with a Horiba XploRA Raman microscope equipped with three diode lasers $(532 \mathrm{~nm}$ @25 mW, 638 nm @24 mW and 785 nm @90 mW) and a thermoelectrically cooled CCD detector. Measurement conditions were optimized for each sample and spot. The analyses were generally carried out with a $100 \times$ microscope objective, a 1200 line $/ \mathrm{mm}$ grating, laser powers between 0.1 and $50 \%$, and accumulation times of 5 to $60 \mathrm{~s}$.

\section{SEM-EDS}

SEM-EDS analyses on samples S1-3 were performed on the carbon-coated cross-sections with a FE-SEM Zeiss Eigma HD, equipped with an Oxford Instrument $\mathrm{X}-\mathrm{Max}^{\mathrm{N}} 80$ SDD detector. Backscattered electron (BSE) images, energy-dispersive spectrometry (EDS) analysis, and X-ray mapping were carried out with an accelerating voltage of $20 \mathrm{kV}$ in high vacuum.

SEM-EDS analyses on the samples housed in Munich (FC5a, FC7a and FC9a) were undertaken after carboncoating in a FEI Quanta 250 with an integrated EDAX SDD-Detektor Apollo XL and Genesis-Software Version 6.31. Measurement conditions were high vacuum mode, 
$25 \mathrm{kV}, 30 \mu \mathrm{A}, 1000 \mathrm{cps}, 100 \mathrm{~s}$ live time, and standardless ZAF quantification.

\section{Results \\ X-radiography}

As mentioned in the Introduction, the original canvas support was lined to a linen fabric with an aqueous glue/ paste adhesive and stretched onto a keyable stretcher before it was purchased in 1919 by Henry Clay Frick [1]. The original tacking margins are lost. An X-radiograph of the entire painting reveals that the original support consists of a plain weave fabric (Fig. 1b). Cusping visible around the perimeter extends five $\mathrm{cm}$ into the picture plane [8], indicating that the original dimensions of the composition have been retained and that the canvas had been stretched before the application of the off-white colored ground. The ground preparation consists of at least two applications. One layer appears less dense and extends to the perimeter. A slightly denser layer with an irregular border stops approximately between 5 and 6 $\mathrm{cm}$ short of the perimeter. A pinprick that may have been used as a vanishing point is visible as a small point of low density on the highlighted fold of the maid's apron to the left of glass. This pinprick is visible on the surface of the paint at a position $31 \mathrm{~cm}$ up from the lower perimeter, which is $1 / 3$ the height of the painting (Additional file 1: Fig. S1).

\section{Infrared imaging}

An infrared photograph taken in 1952 did not reveal the lower portion of the paint stratigraphy. It did show some curtain folds and some indistinguishable features below
(Fig. 2a) [1]. Infrared reflectography (IRR) carried out for this study clearly revealed Vermeer's initial compositional design for the background that will be discussed in detail below (Fig. 2b).

\section{Macro-XRF}

Elemental distribution maps for calcium $(\mathrm{Ca})$, lead $(\mathrm{Pb})$, iron $(\mathrm{Fe})$, copper $(\mathrm{Cu})$ and potassium $(\mathrm{K})$ obtained by MA-XRF are shown in Fig. 3b-f. In these maps, compositional features in the background that were later covered with the curtain are visible, particularly in the Fe distribution map (Fig. 3d).

\section{New sampling}

Three samples, labeled S1, S2 and S3, were taken from the background, in the top edge of the painting, to assist the interpretation of the features observed in the IRR and elemental distribution maps, in order to determine the location of these features in the layer structure, as well as the pigment mixtures. The approximate locations of these samples are indicated in Fig. 3a. Photomicrographs of two of these samples, S1 and S2, taken with visible and UV illuminations and backscattered electron images, are shown in Fig. 4. Photomicrographs of sample S3, which was found to have a similar stratigraphy as sample $\mathrm{S} 2$, are included in Additional file 1: Fig. S2.

In sample S1, Raman spectroscopy and SEM-EDS analyses showed that the main components of the ground preparation (layer 1 in Fig. 4b) are lead white and calcite, and that particles of umber, with $\mathrm{Fe}, \mathrm{Mn}, \mathrm{Si}$ and $\mathrm{Ca}$ as main components, make this ground visually appear off-white. In the layer applied directly over the ground
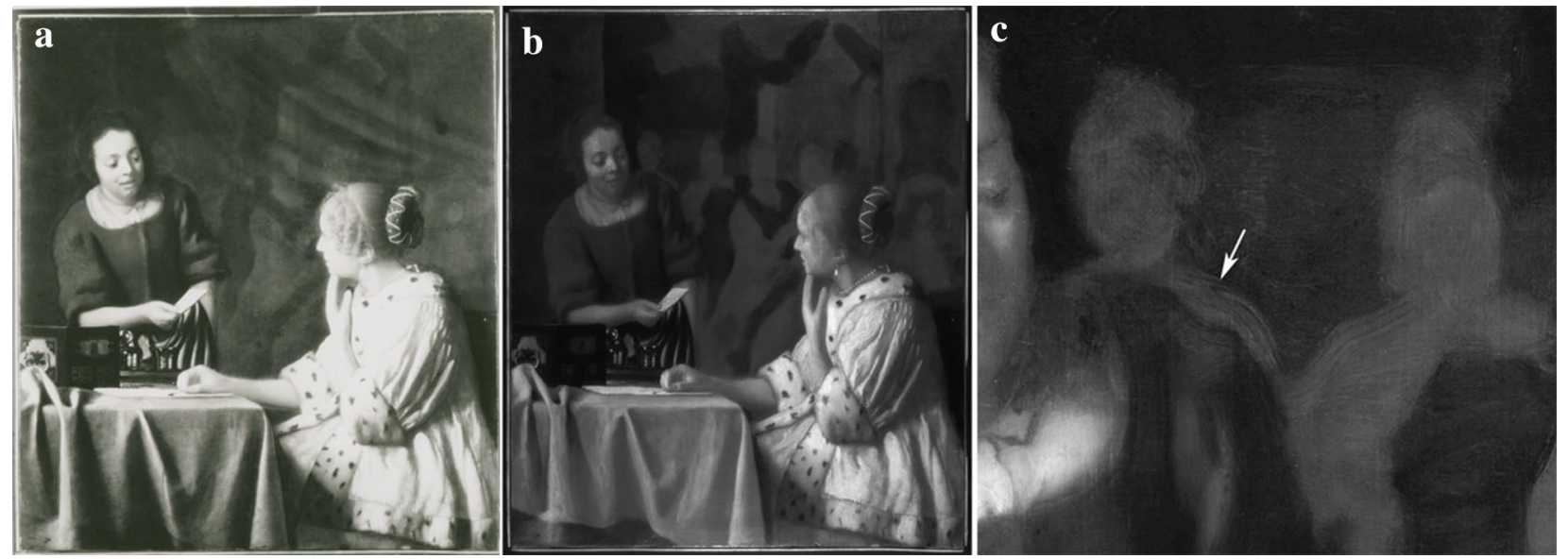

Fig. 2 Johannes Vermeer (1632-1675), Mistress and Maid, 1666-1667. The Frick Collection, New York. Infrared photograph. Suhr, William. Preliminary Report, December 5, 1952. The Frick Collection/Frick Art Reference Library Archives (a). Infrared reflectogram (b). Detail of the reflectogram shown in b, where the white arrow indicates a continuous brushstroke extending around the contour of the maid's shoulder, confirming that the first idea for the background was sketched in after the foreground figures were established (c) 


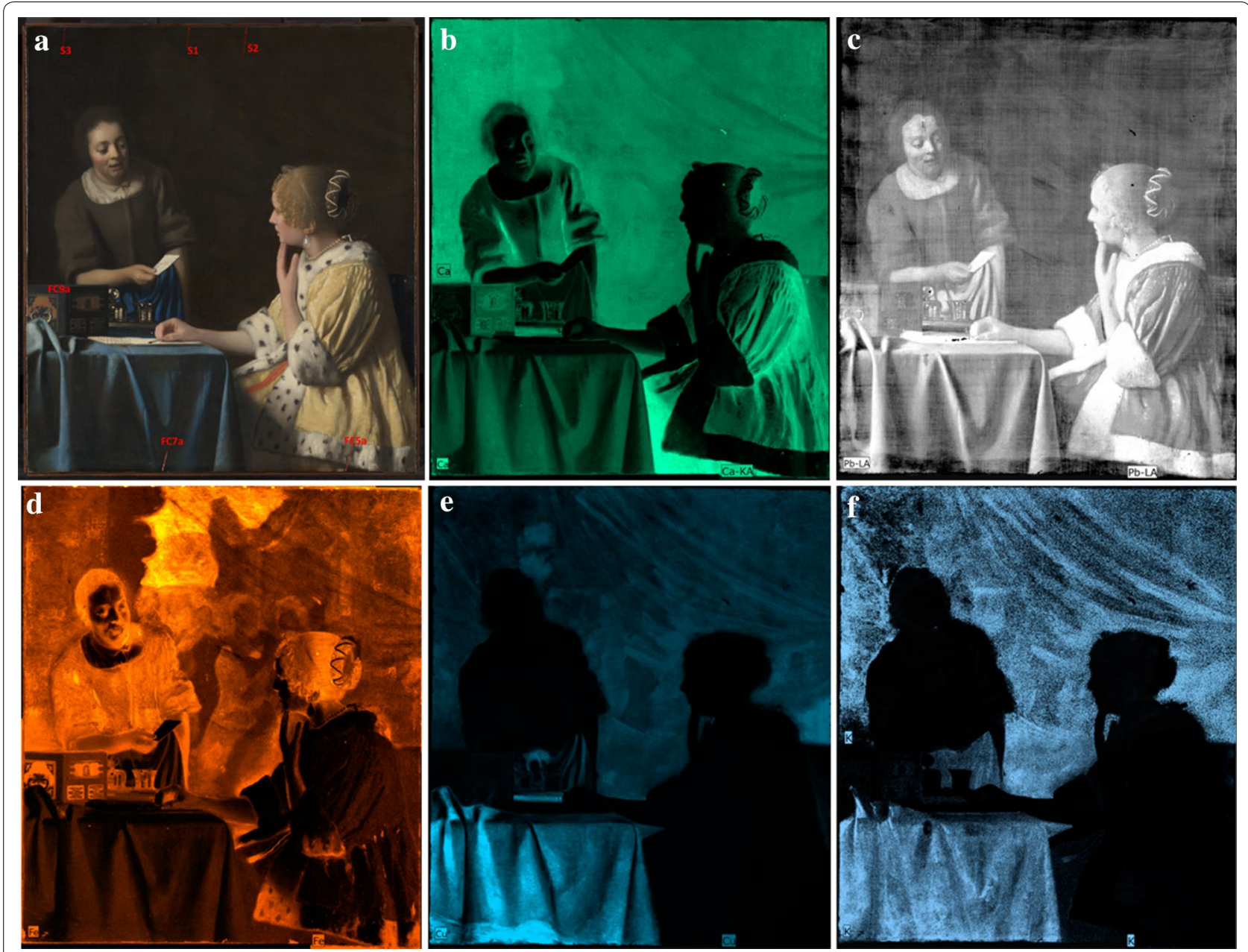

Fig. 3 Johannes Vermeer (1632-1675), Mistress and Maid, 1666-1667. The Frick Collection, New York. The arrows show the approximate locations where microsamples were taken from (a). Ca (b); Pb (c), Fe (d), Cu (e), and K (f) distribution maps acquired by MA-XRF

preparation (layer 2 in Fig. 4b), a carbon-based black pigment, an ochre, relatively minor amounts $\mathrm{Cu}$, possibly in the form of a $\mathrm{Cu}$-based green pigment, traces of calcite and gypsum, and a few lead-tin yellow particles were detected. The presence of P observed by EDS in this layer indicates that the carbon-based black is likely a bone or an ivory black pigment. In the two layers above (layers 3 and 4 in Fig. 4b), Raman analysis identified indigo, and SEM-EDS detected abundant calcium carbonate in the form of chalk, some gypsum, small particles of lead white, some $\mathrm{Cu}$-containing particles, likely a $\mathrm{Cu}$-based green such as a verdigris or $\mathrm{Cu}$ resinate, also associated to $\mathrm{Al}, \mathrm{Ca}, \mathrm{S}, \mathrm{P}$, and $\mathrm{K}$.

In sample $\mathrm{S} 2$, a similar composition was observed for the ground preparation (layer 1 in Fig. 4e) as in sample S1. Layer 2 was found to contain abundant carbon-based black (a bone or an ivory black), along with quartz and ochre particles containing $\mathrm{Si}, \mathrm{Al}, \mathrm{K}$ and Fe. Relatively small amounts of $\mathrm{Cu}$ were detected in this layer, however it is not possible to rule out that these are the result of contamination from the upper layers in the sample. In the layers 3 and 4, indigo was detected, along with abundant calcium carbonate in the form of chalk, small particles of lead white, some gypsum, and particles of a $\mathrm{Cu}$-based pigment, such as verdigris or $\mathrm{Cu}$ resinate, also containing $\mathrm{Al}, \mathrm{S}, \mathrm{P}, \mathrm{K}$ and $\mathrm{Ca}$. The main compositional difference between layers 3 and 4 is that in layer 3 the calcium carbonate particles are more finely divided.

\section{Re-examination of the samples taken by Kühn in 1965}

Of the samples taken in 1965 by Hermann Kühn [7], three cross-sections, labeled FC5a, FC7a, and FC9a, taken from the spots indicated in Fig. 3a, were re-analyzed by SEM-EDS and partially by Raman spectroscopy for the present study.

In these samples, the composition of the ground preparation was found to be similar to the one observed in samples S1 and S2. Samples FC5a and FC7a show, 

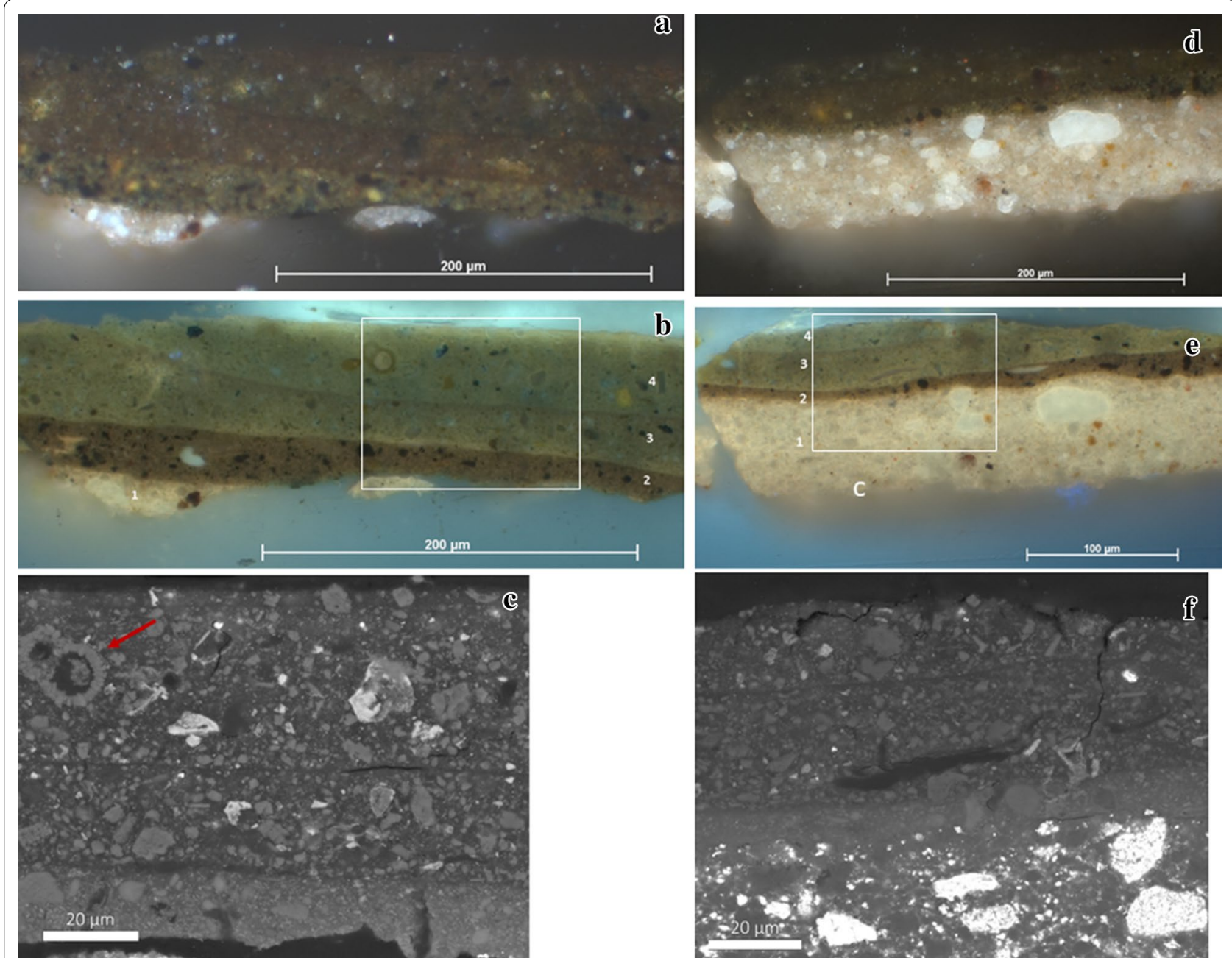

Fig. 4 Photomicrographs of paint-cross sections taken from the curtain area, approximately from the locations indicated in Fig. 3a. Sample S1 taken with visible (a) and with UV illumination (b), original magnification $\times 400$; and electron backscattered image detail (c) taken with a $\times 1063$ magnification in the rectangle included in $\mathbf{b}$. The arrow in $\mathbf{c}$ indicates the location of a foraminifer. Sample S2, taken with visible (d) and with UV illumination (e), original magnification $\times 400$; and electron backscattered image detail $(\mathbf{f})$ taken with $a \times 1067$ magnification in the rectangle included in e

on top of the ground, a brown-black layer of similar composition containing a mixture of a bone black and calcium carbonate, with relatively small amounts of lead-tin yellow, lead white, and red lake (containing $\mathrm{Al}, \mathrm{K}$, and S) (Fig. 5a, d). In the yellow paint layer in sample FC5a (Fig. 5a-c), taken from the mistress' yellow garment, a mixture of lead-tin yellow type I and an organic colorant on a calcium carbonate substrate, most likely a yellow lake, also containing relatively minor amounts of $\mathrm{Al}, \mathrm{K}, \mathrm{Cl}, \mathrm{S}, \mathrm{P}$, was observed. In this layer, other minor components include ultramarine blue, bone black, ochre, vermilion, gypsum and lead white. When the sample is viewed at a higher magnification, particularly under UV illumination, a relatively thin, 2 to $3 \mu \mathrm{m}$ thick portion at the top of the stratigraphy appears slightly faded (Additional file 1: Fig. S6).

Sample FC7a was taken from the tablecloth (Fig. 3a). In this sample, over the brown-black layer that is right over the ground preparation (layer 2 in Fig. 5f), a layer that appears mainly organic in nature in the backscattered electron image (layer 3 in Fig. $5 \mathrm{f}$ ) is composed mainly of $\mathrm{C}, \mathrm{O}$, and $\mathrm{Cu}$, along with some $\mathrm{Cl}, \mathrm{Ca}, \mathrm{Al}, \mathrm{K}$, and $\mathrm{S}$. These results indicate that the layer contains, most likely, a $\mathrm{Cu}$ based green pigment such as verdigris or $\mathrm{Cu}$ resinate. In the four layers right above layer 3 , ultramarine blue was observed (layers 4-7 in Fig. 5f). In layer 4, the ultramarine blue is mixed with lead-tin yellow, a vegetable black, lead white, and calcium carbonate. In layer 5, calcium 

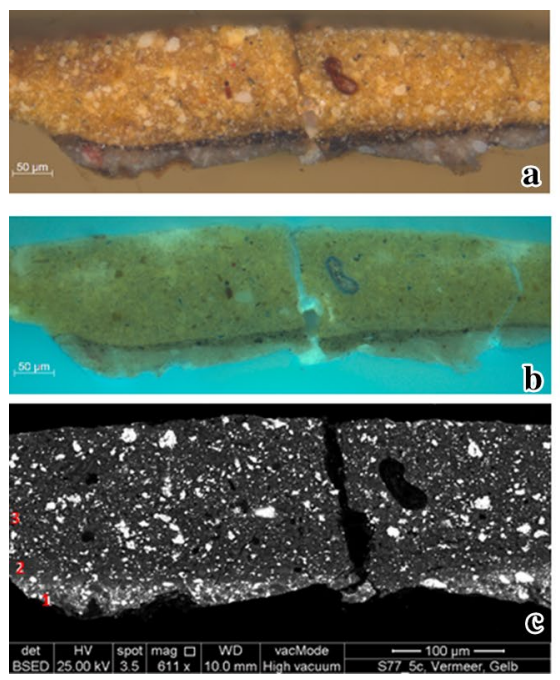
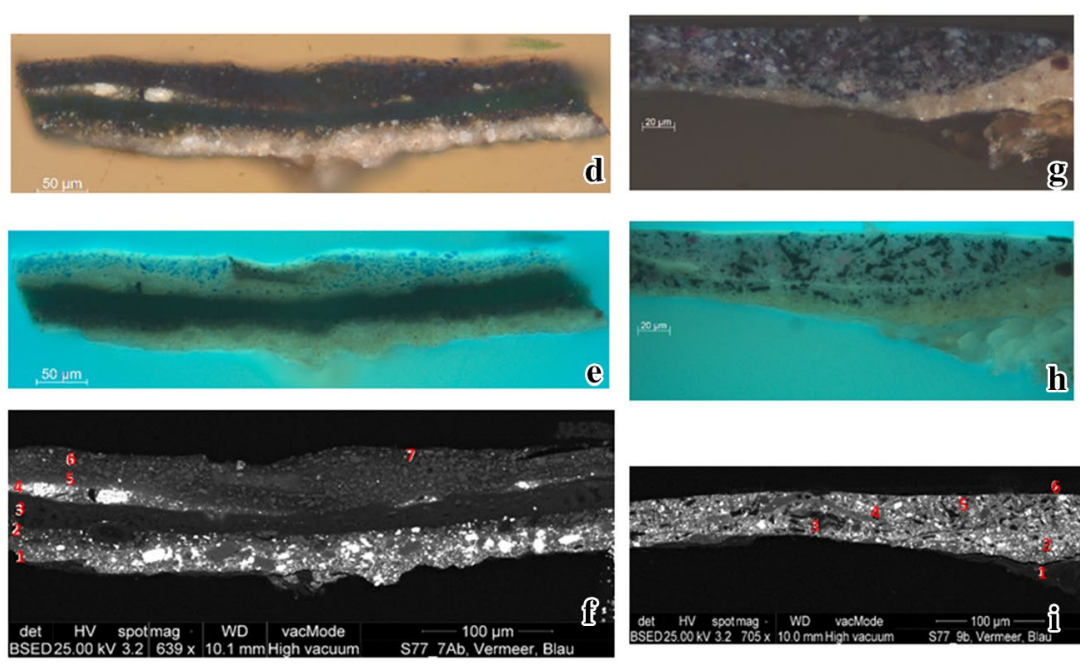

Fig. 5 Photomicrographs of paint-cross sections taken in the 1968 study by Hermann Kühn, approximately from the locations indicated in Fig. 3a. Sample FC5a, taken with visible (a) and with UV illumination (b), original magnification $\times 200$, and electron backscattered image, $\times 611$ (c); sample FC7a, taken with visible $(\mathbf{d})$ and with UV illumination (e), original magnification $\times 200$, and electron backscattered image, $\times 639$ (f); and sample FC9a taken with visible $(\mathbf{g})$ and with UV illumination $(\mathbf{h})$, original magnification $\times 500$, and electron backscattered image, $\times 705(\mathbf{i})$

carbonate and relatively small amounts of an ochre are mixed with the ultramarine blue; in layer 6, ultramarine blue with calcium carbonate and relatively smaller amounts of lead white are present; and in the thin layer 7 , ultramarine blue is the main component. In these four layers at the top of the stratigraphy, Raman spectroscopy did not show bands characteristic of indigo, but its presence cannot be completely ruled out. The relatively large amounts of calcium carbonate found in the layers could be due to the substrate of a yellow lake, but this could not be determined with certainty with the techniques used.

In the sample FC9a, taken from the veneered box (Figs. $3 \mathrm{a}$ and $5 \mathrm{~g}-\mathrm{i}$ ), components in layer 1 are remnants of an organic layer, presumably sizing, and layer 2 is the ground preparation, which was found to have a composition similar to the one observed for the samples discussed above. Layer 3-today a greyish-blue, was found to be composed of a vegetable black, lead white, calcium carbonate and few pink particles containing $\mathrm{Al}, \mathrm{S}$ and $\mathrm{K}$, most likely a red lake. Raman analysis in this layer did not give bands expected for indigo. The thin layer 4, that appears bright under UV illumination (Fig. 5h), is mainly organic, and contains few ultramarine blue and lead white particles. The final paint layer 5 resembles layer 3 in color and composition and contains a mixture of vegetable black, lead white, and pink particles composed of relatively large amounts of $\mathrm{Al}$, and minor quantities of S, K, and P, most likely a red lake, along with a minor amount of ultramarine blue and few particles of a probably secondary phase containing $\mathrm{K}, \mathrm{S}$, and $\mathrm{Pb}$. An organic layer, most likely a varnish, is present at the top of the stratigraphy (Fig. 5h, labeled as layer 6 in Fig. 5i).

\section{Discussion}

The brown-black layer observed in the samples FC5a, FC7a and FC9a by Kühn is an indication of Vermeer's practice of beginning his compositions in neutral dark tones, and has subsequently been observed in other studies on Vermeer paintings [9-11]. This layer is similar to the dark undermodelling present in the three samples taken for the present study.

This dark layer right above the ground in samples S1 and S2 (layers labeled as 2 in Fig. 4b, e), containing bone or ivory black, ochre, along with relatively minor amounts of $\mathrm{Cu}$ as mentioned in the Results section, corresponds to an early and unresolved composition made visible through IRR (Fig. 2b) and MA-XRF (Fig. 3b-f). It is important to note that samples $\mathrm{S} 1$ and $\mathrm{S} 2$ do not show an intermediate layer of varnish or dirt between the dark layer of the first composition and the subsequent paint layers of the curtain, which implies that both were part of Vermeer's painting process in developing-and changing-the composition.

\section{The background}

Like many artists, Vermeer made modifications in the course of developing his compositions. The elemental distribution maps obtained by MA-XRF are revealing as they show that Vermeer included a highly detailed, multi figural pictorial element in the background, with 
at least four figures, that he later painted out. This section likely represented a large tapestry or painting on the wall behind the figures. Mistress and Maid would have appeared strikingly different had Vermeer retained this pictorial element in the final composition. After deciding that a relatively dark and plain background would better focus on the women's interactions, he added the curtain, drawn aside to direct attention on the letter's receipt. Vermeer frequently embellished his painted interiors with items such as maps, mirrors, paintings, and tapestries [2, 12, 13]. For example, in Woman Holding a Balance, 1663-1664 [6], in the collection of the National Gallery of Art, Washington, the woman's action is contrasted with a large Last Judgment painting on the wall behind [14]. In other cases, like in Girl with a Red Hat, 1665-1667 [6], also in the National Gallery of Art, Washington [15], painted slightly before Mistress and Maid, a section of a tapestry is visible.

The hypothesis that the original figural elements in the background of Mistress and Maid were from a tapestry would explain the vertical section to the far right of the design evident in the reflectogram (Fig. 2b) (see also, Additional file 1: Fig. S3). This section seems to depict a sculpture in a niche and would make sense as an elaborate border surrounding the tapestry's central scene [2]. Although the original source of Vermeer's inspiration for the background has not been identified, a Flemish tapestry woven after designs by Jacob Jordaens (1593-1678) is a useful comparative [2]. Here one finds a robust female figure in a posture reminiscent of the one visible in the IRR image of Mistress and Maid, near the mistress's profile. Hanging garlands and borders populated with statues also correspond to elements discernible in the IRR. It is also possible that the unresolved portion of the composition was a painting hanging on the wall. Some of the contours of the figures are similar to those in a painting, the subject of which has been described as the finding of Moses [16], that appears on the wall in two other Vermeer compositions: The Astronomer, 1668 [6], in the Musée du Louvre, and A Lady Writing a Letter with Her Maid, 1670-1671 [6], National Gallery of Ireland, Dublin. Whatever this intricate design was intended to depict, Vermeer possibly felt that it distracted from the central narrative and edited it out of the final composition.

Close inspection of the IRR, supported by the MAXRF analysis, confirms that this early idea for the background was blocked-in after the foreground figures had already been established. The IRR shows a continuous brushstroke in one of the background features extending around the contour of the maid's shoulder (Fig. 2c. Also, see, Additional file 1: Fig. S3). In addition, the Fe distribution map reveals a fairly clear image of the features in the tapestry (Fig. 3d). This indicates that this pattern was only sketched in neutral tones containing black and earth colors with one exception: there is a slight indication of a few features in the $\mathrm{Cu}$ distribution map (Fig. 3e), possibly painted in a greenish or bluish hue.

The presence of single dark layer over the ground in the three samples taken from the upper edge (S1, S2 and S3) suggest that the tapestry was only blocked-in in neutral dark tones before the artist changed his mind and decided to paint a curtain extending over the entire background. The $\mathrm{Ca}, \mathrm{Pb}, \mathrm{Fe}, \mathrm{Cu}$ and $\mathrm{K}$ maps reveal the sweeping diagonal forms of a curtain hanging behind the foreground figures (Fig. 3b-f). The curtain modeled on top of the underlying design is intentional, and clearly integral to the final composition. Examination of the surface under magnification showed that the curtain was painted before the artist made final touches to the foreground figures. See, for example, a detail showing the mistress' hair finished on top of background in Fig. 6 .

But, why does the curtain now appear so diminished in form and is dark brown in color? The $\mathrm{Cu}$ distribution map suggests that the original color was most probably green. Examination of the surface with the stereomicroscope reveals particle agglomerates that retain the translucent green color typical of $\mathrm{Cu}$-based green pigments, such as verdigris or $\mathrm{Cu}$ resinate (Additional file 1: Fig. S4). The analysis of the three new cross sections taken from the background proved essential in demonstrating the original color of the curtain and in characterizing the reason for the significant color change.

The two top layers in the cross-sections S1, S2 and S3 correspond to the curtain, and are composed of indigo, some particles of a $\mathrm{Cu}$-based green pigment, such as a verdigris or $\mathrm{Cu}$ resinate, containing $\mathrm{Al}, \mathrm{Ca}, \mathrm{S}, \mathrm{P}$, and $\mathrm{K}$ in addition to $\mathrm{Cu}$, and abundant calcium carbonate in the form of chalk, some gypsum, and small particles of lead white. This composition indicates that, most likely, the curtain was initially a dark translucent green. Its present dark brown appearance is the result of the discoloration of the $\mathrm{Cu}$-based green pigment. Because the original mixture was composed primarily of a transparent $\mathrm{Cu}$ based green with the addition of indigo and just a small amount of lead white to achieve enough opacity to cover the features in the underlying composition, the darkening also resulted in a significant loss of form.

The presence of $\mathrm{K}$ in the curtain (Fig. 3f) may be due in part to the recipe used to make the $\mathrm{Cu}$-based green pigment. Woudhuysen-Keller and Woudhuysen mention a recipe in Birelli's 1601 Florentine treatise on painting [17] which calls for the addition of verdigris ground in oil to alum 'dissolved' in hot oil to make 'a green resembling emerald'. It should be stressed that $\mathrm{K}$ was detected by SEM-EDS in the $\mathrm{Cu}$-based green pigment particles as mentioned above. It is also important to note that there 

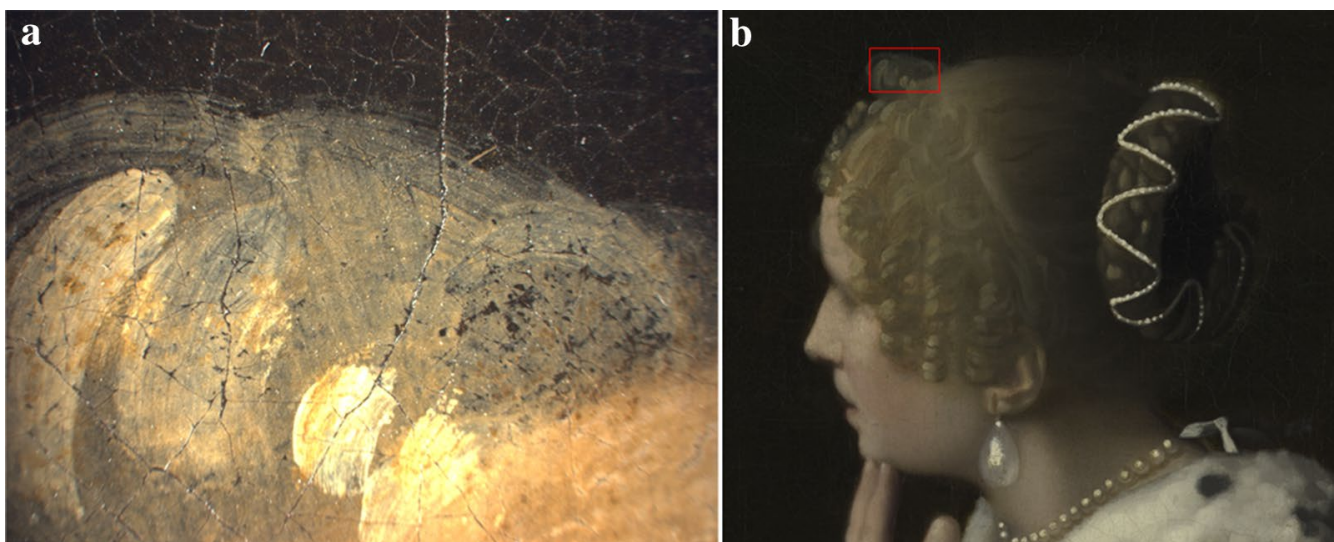

Fig. 6 a Photomicrograph taken in the area indicated by a red rectangle in $\mathbf{b}$, showing that the Mistress' hair is painted over the curtain in the background. Original magnification $\times 60$

is $\mathrm{K}$ in the tablecloth, the significance of this is discussed below. We cannot rule out that some of the Ca present is due to the substrate of an organic yellow lake that has now faded. Presently, relatively larger samples than the ones taken in the present study are needed for the chromatographic analysis of yellow colorants in order to provide a more definitive answer.

\section{The tablecloth}

Although the tablecloth appears to be blue, passages of an original bright transparent green along the left perimeter of the painting that had been protected from light exposure were observed when the painting was examined with a stereomicroscope (Fig. 7a). This observation raised questions as to whether there had been a color change here as well. The presence of the softly draping folds of the tablecloth in the $\mathrm{Cu}$ distribution map support the detection of a $\mathrm{Cu}$-based green pigment reported by Hermann Kühn as a $\mathrm{Cu}$ resinate [7]. While the shadows of the tablecloth appear a greenish brown, the highlights are bright blue (see Additional file 1: Fig. S5). Examination of the highlights with a stereomicroscope reveals bright blue particles glazed on top of a light underlayer (Fig. 7b). Revisiting the cross-sections from Kühn's study was essential to determining the artist's original intentions in this passage. Sample FC7a contains seven layers (Fig. $5 \mathrm{~d}-\mathrm{f}$ ), as described in the Results section. On top of the ground, there is a layer of a dark toning or undermodelling followed by a layer containing a $\mathrm{Cu}$-based green. The subsequent layers are different mixtures all containing ultramarine blue, two of these layers contain yellow pigments, lead-tin yellow or ochre, and therefore are a green hue. The top two layers contain ultramarine blue, but an admixture with a yellow lake on a chalk
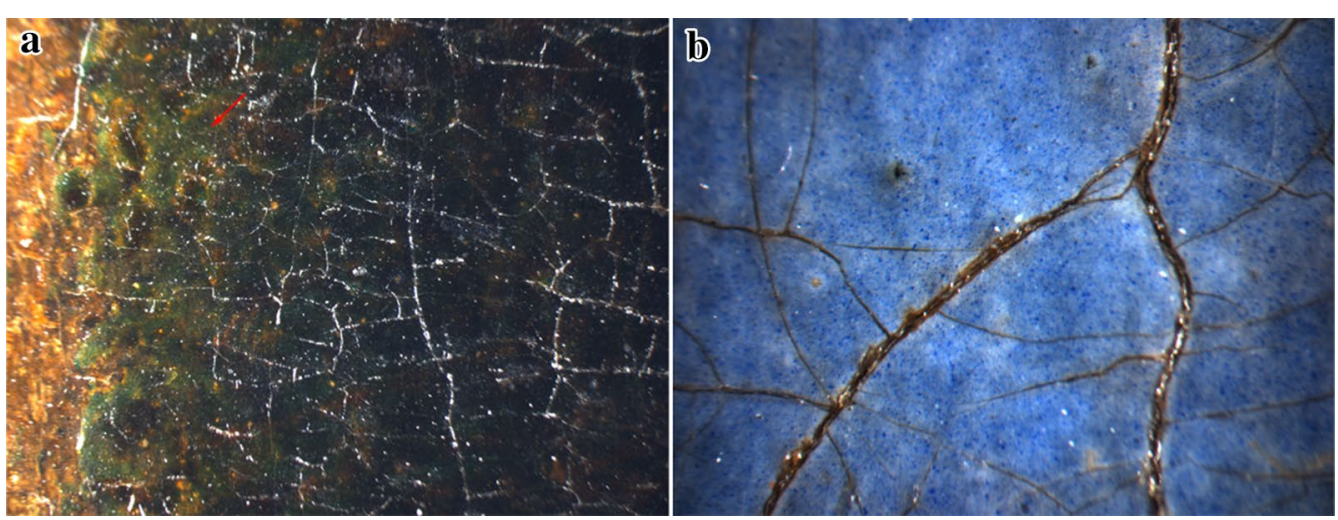

Fig. 7 Photomicrograph taken in the left perimeter of the tablecloth, where a small area of the green color that was preserved, possibly because it was protected from light by a frame, is indicated with a red arrow. Original magnification $\times 165$. The approximate location where this image was taken from is indicated in Additional file 1: Fig. S5 (a). Photomicrograph taken in a highlight area of the tablecloth showing the particles of ultramarine blue glazed over a white underlayer. Original magnification $\times 480$ (b) 
substrate cannot be ruled out. Perhaps most interesting is that layer 7 contains only ultramarine blue particles distributed in a medium rich layer, judging from the bright fluorescence when the sample is viewed under UV illumination and the SEM-EDS results, which suggest that this is the final glaze.

Summarizing, the visual remains of the bright green preserved along the edge, the brownish green appearance of the shadows, and the presence of a $\mathrm{Cu}$-based green indicate that the tablecloth was originally intended to be green. The present blue appearance is due to the preservation of the ultramarine mixtures containing lead white and, possibly, to the fading of a yellow lake in the final glaze containing ultramarine blue. The characterization of this color change is further supported by the fact that Vermeer's estate inventory includes a green tablecloth [18].

\section{The mistress' yellow jacket and robe}

At the top of the sample FC5a, a slightly faded yellow lake pigment is observed to a depth of $2-3 \mu \mathrm{m}$ by optical microscopy (see Additional file 1: Fig. S6). Although the mistress' yellow satin jacket and robe still appear yellow, the microscopic analysis indicates that the original color must have somewhat diminished to a degree due to the fading of the yellow lake component at the surface. The overall color is preserved due to the presence of lead-tin yellow and the preserved yellow lake in the depths of the paint layer. Vermeer's characteristic dark undermodelling can be observed in the half-tones and shadows of the mistress' yellow satin jacket (see Additional file 1: Fig. S7).

\section{Conclusions}

Since the nineteenth century, with the growth in the number of studies focusing on Vermeer's paintings, critics and scholars have struggled to understand the visual peculiarities presented by Mistress and Maid. The relatively recent development of imaging techniques and the improvement in the sensitivity of microanalytical methods have allowed us to address the questions and resolve misunderstandings. The evolution of this unusually large-scale composition and figures that began with a tapestry or painting filling the background- an astonishing new discovery- can now be understood as consistent with other examples in the artist's oeuvre. This technical study has also established with certainty that the curtain is original. The characterization of a significant change in the original color and form of the curtain, which resulted in previous speculation that the painting was left in an unfinished state, can finally be put to rest. Perhaps most remarkable is, despite the significant changes, the painting is still admired as a powerful and evocative depiction. The blue tablecloth is not less appealing now that we know it was originally green, and retains its modelling and visual impact. Knowledge of the original color is not surprising because Vermeer's estate inventory includes a green tablecloth, and he was an artist keenly interested in direct observation. It seems probable that he modeled elements of this composition after objects in his possession-just another aspect that may bring us closer to this magnificent artist as we hope this technical investigation has done.

\section{Supplementary information}

Supplementary information accompanies this paper at https://doi. org/10.1186/s40494-020-00375-2.

Additional file 1. Additional figures.

\section{Abbreviations}

FTIR: Fourier transform infrared spectroscopy; IRR: Infrared reflectography; MAXRF: Macro-X-ray fluorescence or XRF mapping; SEM-EDS: Scanning electron microscopy-energy dispersive X-ray spectroscopy; UV: Ultraviolet.

\section{Acknowledgements}

The authors are grateful to Evan Read, Associate Manager of Technical Documentation in the Paintings Conservation Department at The Met for his assistance, to Christoph Steuer and Ursula Baumer at the Doerner Institut for the Raman analysis and the FTIR analysis of the green pigment in the samples housed in Munich, and to Xavier Salomon and Esmée Qodbach, The Frick Collection, Maryan Ainsworth, The Met, and Arthur K. Wheelock Jr., formerly at The National Gallery of Art, Washington DC, for helpful discussions.

\section{Authors' contributions}

All authors contributed to interpreting the analytical results and were involved in drafting the manuscript. SC run the MA-XRF, the Raman spectroscopy measurements on the paint cross-sections taken at The Met, and contributed to the examination of these samples by optical microscopy. FC run the SEM-EDS analysis on the samples taken at The Met, and HS and AO analyzed the samples housed in Munich. DM contributed with the conservation perspective and the examination of the Met samples by optical microscopy. Ml contributed with the art historical perspective. All authors read and approved the final manuscript.

\section{Funding}

All funding was from internal Metropolitan Museum of Art, Frick Collection, and Doerner Institut funds.

\section{Availability of data and materials}

The datasets acquired at The Met are available from the corresponding author and the data acquired at the Doerner Institut is available from HS, on reasonable request.

\section{Competing interests}

The authors declare that they have no competing interests.

\section{Author details}

${ }^{1}$ Department of Paintings Conservation, The Metropolitan Museum of Art, 1000 Fifth Avenue, New York, NY 10028, USA. ${ }^{2}$ Department of Scientific Research, The Metropolitan Museum of Art, 1000 Fifth Avenue, New York, NY 10028, USA. ${ }^{3}$ The Frick Collection, 1 East 70th Street, New York, NY 10021, USA. ${ }^{4}$ Scientific Department, Doerner Institut, Bavarian State Painting Collections, Barer Str. 29, 80799 Munich, Germany. 
Received: 30 January 2020 Accepted: 17 March 2020

Published online: 27 March 2020

\section{References}

1. Suhr W. Record of Treatment by Mr. William Suhr, December 1952-September 1953; Vermeer Mistress and Maid The Frick Collection/Frick Art Reference Library Archives 1952-1953 Contract No.: 126.

2. lacono M, Ivory J. Vermeer's Mistress and Maid. New York: The Frick Collection and D. Giles Ltd.; 2018.

3. Blankert A, Montias JM, Aillaud G. Vermeer. New York: Harry N. Abrams; 2007.

4. Wheelock AK Jr. Vermeer \& the Art of Painting. New Haven: Yale University Press; 1995.

5. Le Brun JBP. Recueil de gravures au trait, à l'eau-forte, et ombrées, d'après un choix de tableaux de toutes les écoles, recueillis dans un voyage fait en Espagne, au midi de la France et en Italie, dans le années 1807 et 1808. Paris: De Didot jeune; 1809.

6. Vermeer Liedtke W. The Complete Paintings. Brussels: Ludion; 2008.

7. Kühn H. A study of the pigments and the grounds used by Jan Vermeer. Rep Stud Hist Art. 1968:2:154-75.

8. Johnson Jr. CR, Noble PN, Verslype I, Franken M, Wheelock A, Sethares B. Counting Vermeer: using weave maps to study Vermeer's Canvases. 2017 http://countingvermeer.rkdmonographs.nl/appendix-i-paintings-repor ts-and-X-radiographs/I21-mistress-and-maid.

9. Wadum G, Hoppenbrouwers R, van der Loeff L. Vermeer Illuminated Conservation, Restoration and Research. The Hague: V+K Publishing/Inmerc; 1994.

10. Groen KM, van der Werf ID, van den Berg KJ, Boon JJ. Vermeer Studies Scientific Examination of Vermeer's 'Girl with a Pearl Earring'. In: Gaskel
I, Jonker M, editors. Studies in the History of Art. Washington: National Gallery of Art; 1998. p. 168-83.

11. Vandivere A, van Loon A, Dooley KA, Haswell R, Erdmann RG, Leonhardt E, et al. Revealing the painterly technique beneath the surface of Vermeer's Girl with a Pearl Earring using macro- and microscale imaging. Heritage Sci. 2019;7(1):64.

12. Weber GJ. Vermeer's use of the picture-within-a-picture: a new approach Washington DC: The National Gallery of Art; 1998. p. 294-307.

13. Welu JA. Vermeer: his Cartographic Sources. The Art Bulletin. 1975;57(4):529-47.

14. Wheelock Jr AK. Woman Holding a Balance. Washington DC: National Gallery of Art, Washington; 2017. https://www.nga.gov/collection/art-objec t-page.1236.html. Accessed 11 Dec 2019.

15. Wheelock Jr AK. Johannes Vermeer/Girl with the Red Hat/c. 1665/1666. National Gallery of Art Editions Online 2014. https://purl.org/nga/colle ction/artobject/60. Accessed 10 Dec 2019.

16. Foucart J. Peter Lely, Dutch History Painter. Hoogsteder-Naumann. Mercury. 1989:8:17-26.

17. Woudhuysen-Keller R, Woudhuysen P. Thoughts on the use of the green glaze called 'Copper Resinate' and its colour-changes. In: Hermens AO, Kostaras N, editors. Looking through paintings. London: Archetype; 1998. p. 133-46.

18. Montias JM. Vermeer and his Millieu: a web of social history. Princeton: Princeton University; 1989.

\section{Publisher's Note}

Springer Nature remains neutral with regard to jurisdictional claims in published maps and institutional affiliations.

\section{Submit your manuscript to a SpringerOpen ${ }^{\circ}$ journal and benefit from:}

- Convenient online submission

- Rigorous peer review

- Open access: articles freely available online

- High visibility within the field

- Retaining the copyright to your article

Submit your next manuscript at springeropen.com 